\title{
Three Phase Eleven Level Modular Multilevel Inverter with PD-PWM for Grid Connected System
}

\author{
P Yogini ${ }^{1} \mid$ Dr. Sujatha Balaraman ${ }^{2}$
}

${ }^{1}$ PG Scholar, Department of EEE, Government College of Technology, Coimbatore, Tamil Nadu, India

${ }^{2}$ Associate Professor, Department of EEE, Government College of Technology, Coimbatore, Tamil Nadu, India

\section{To Cite this Article}

P Yogini and Dr. Sujatha Balaraman, "Three Phase Eleven Level Modular Multilevel Inverter with PD-PWM for Grid Connected System", International Journal for Modern Trends in Science and Technology, 6(8): 86-91, 2020.

\section{Article Info}

Received on 16-June-2020, Revised on 05-July-2020, Accepted on 26-July-2020, Published on 03-August-2020.

\section{ABSTRACT}

The prominence of Modular Multilevel Inverters (MMI) is rising owing their merits of simple mechanical construction and good voltage sharing for semiconductor devices. Mostly Multilevel Inverters use more than one source; however, the effective use of all the sources at all levels is rare. Conventional Multilevel Inverters will diminish the energy efficiency of the conversion system. When compared to conventional multilevel inverter, Modular Multilevel Inverter with a high numbers of voltage levels seem to be the most suitable because of the use of an isolated dc source. This paper explores a three-phase eleven level modular multilevel inverter with phase disposition pulse width modulation technique (PD-PWM) that can extract power from all the sources at all the levels. Besides, this paper develops a synchronous $d$-q reference frame controller to control the current of $11 \mathrm{kV}$. When compared with Reduced Switch Count based Multilevel Inverter Series/Parallel switching topologies, the Modular Multilevel Inverter provides better Total Harmonic Distortion (THD) of output voltage and utilization factor.

KEYWORDS: Modular Multilevel Inverter, phase disposition PWM, THD, synchronous d-q reference frame

\section{INTRODUCTION}

Modern power electronic technology plays an important role in distributed generation and the integration of the renewable energy to the power grid. The output power of renewable energy system is mostly dependent on the environment condition, therefore it is necessary to use some control strategies in order to compensate for the fluctuations. One traditional way is to use different kind of converters to integrate the micro sources into a common DC bus.
Power electronics circuits extract utmost power possible from renewable energy sources and inject that power to grid fulfilling the strict grid codes. There are lots of power electronics converters in the system so the harmonics components would be very high, which increases the cost and size of the harmonics filter. In order to overcome this, a modular power electronics technology named multilevel inverter, which is very appropriate for the integrating renewable energy resources. The fundamental role of the multilevel inverter is to achieve the desired ac voltage from several levels of dc voltages. 
The output voltage of the multilevel inverter can reach high level even without the use of transformer. The key benefit is improving the quality of the output voltage, reduced total harmonic distortion and thereby reducing the filtering equipment compared to conventional inverter. The commonly used topologies for the multilevel inverter includes diode clamped inverter, capacitor-clamped, and cascaded multilevel inverter. For higher number of levels in diode clamped and capacitor clamped multilevel inverter requires high number of clamping diodes and flying capacitors which is quite complex. It can be overcome by employing Cascaded H-bridge based topology, however it requires separate dc sources which makes its application limited [1] [2]. There is a recent transition from conventional multilevel Inverter to Reduced Switch Count (RSC) topology [3]. The configuration proposed in [4] is a single phase RSC topology comprises more than one source. By using this, different voltage levels can be through series/parallel switching of sources and improve the utilization of dc sources compared to CHB based topology and it can be extended to three phase [5].Modular multilevel converter (MMC) is highly scalable with respect to the number of levels. Its structure was first proposed byLesnicar and Marquardt in 2003[6]. Since then, the topology had a great attraction for high power and medium to high voltage applications. The advantages include reduction in the need for AC filtering, easy scalability and stress reduction in the semiconductor. However, the presence of circulating current and for capacitor balancing requires additional filter and increased complexity [7].

Regarding the three phase grid-connected renewable systems, several vector control strategies [8-10] like Hysteresis control, dead-beat predictive control and d-q control have been widely used with acceptable results. Among them linear d-q control approach seems to be cheapest strategy as well as easy toimplement. The d-q control strategy implemented in the synchronous reference frame has been the preferable strategy and for this Park's transformation is applied to the three-phase line currents.

Rest of this paper is organized as follows. Section II describes the system configuration. The basic definition and analytical modelling of MMI and the utilization of the sources for MMI and RSC-SSPS topology are assessed in Section III and
IV. The conventional closed-loop control of the MMI and the linearization of the grid-connected MMI system are discussed in Section V. The simulation results for eleven level MMI and comparison results are scrutinized in Section VI. This paper is concluded in Section VII.

\section{LAYOUT OF GRID CONNECTED MMI}

Block diagram of the system considered with three phase MMI, feeding set point real and reactive power ( $\mathrm{P}_{\text {ref }}$ and $\left.\mathrm{Q}_{\mathrm{ref}}\right)$ to the grid is shown in Fig. 1. The closed-loop control of MMI is achieved by employing a PI controller. The controller in turn generates the modulating signal references for MMI, as shown in Fig. 1.

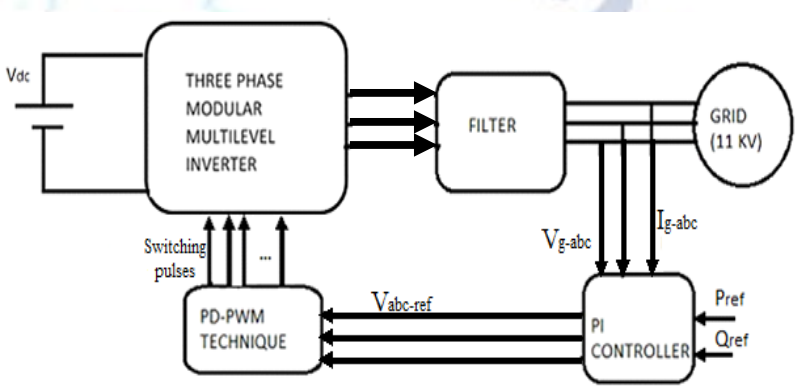

Fig. 1. Schematic diagram of grid connected MMI system

\section{BASICS OF MMI}

Modular Multilevel Inverterstructure is shown in Fig.2, has identical small subsystems that can be easily added to achieve higher power and voltage level with reduced total harmonic distortion. Submodule is the basic building block of MMC. The modularity of modular multilevel converter comes from this basic building block. Each submodule has a well-known half-bridge structure, which consists of one submodule capacitor and two power semiconductors, IGBT.

The submodule capacitor acts as the DC-link capacitor of two-level converter, but it is evenly distributed in the structure of MMI. It behaves as a voltage source and energy buffer. The half-bridge IGBTs chop the capacitor voltage according to PWM commands. The transistors $\mathrm{T}_{1}$ and $\mathrm{T}_{2}$ in the submodule work in at odd way. When $\mathrm{T}_{1}$ is turned on, $\mathrm{T}_{2}$ has to be turned off to prevent shoot-through. When $\mathrm{T}_{1}$ is turned on, the capacitor voltage appears at the submodule terminals. In this condition, the submodule is said to be inserted or else it is said to be bypassed 

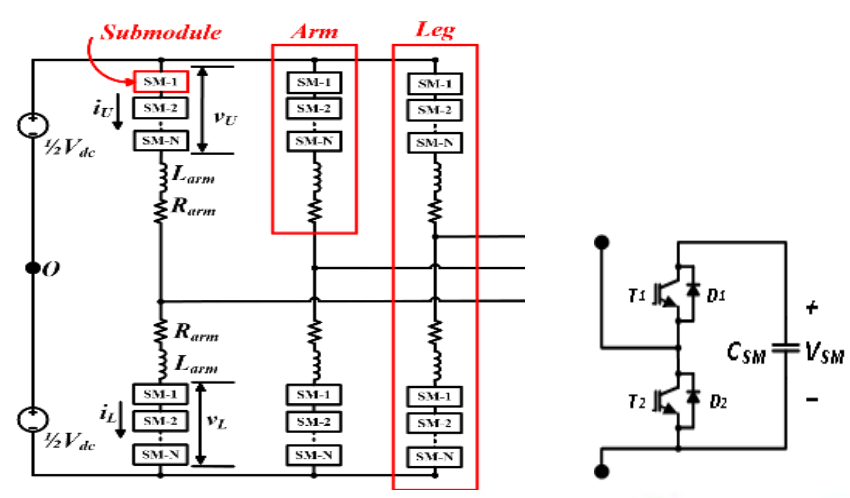

Fig .2: Structure of MMI and sub-module

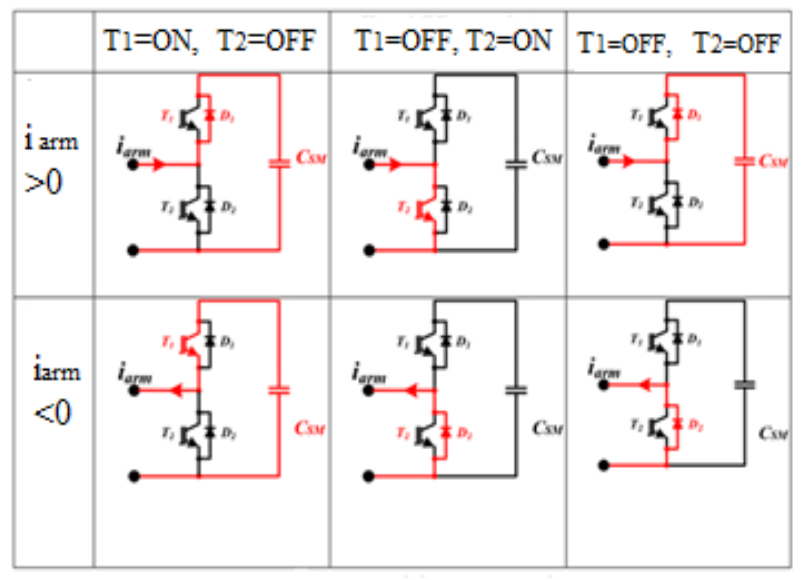

Fig.3: Submodule states and current path

A three-phase two-level converter involves six power semiconductors. MMI replaces each semiconductor in the two-level converter with a structure of a cascaded submodules and an inductor, shown in Fig. 2. This structure is called arm. The structure of cascaded submodules are the basic motive of multilevel voltage appearing at the output. The arm above the output terminal is named upper arm, and the below is named lower arm. The arm inductor isolates theupper and lower arm when they switching and prevents higher current flow between these two arms. The inductor acts as a filter also for output current.

The upper and lower arm forms a leg which is the hardware section of MMI for one phase. Three legs constitute a three-phase MMI as shown in Fig.2. The legs areconnected to a common DC-link. Possible conditions of the arm current (either $i_{U}$ or $i_{L}$ ) direction and the gate signals of submodule semiconductors are shown in Fig.3. It can be deduced that charging and discharging of submodule capacitor occur when $\mathrm{T}_{1}$ is turned on. If the arm current is positive, then the capacitor is charged.In addition, the conditions where both
IGBTs are under off state may represent initial charging of submodule capacitor during start-up.

\section{Analytical Modelling of MMI}

The dynamics and causality relations of MMC can be quite complex. There are several parameters that differently affect the performance in varying conditions. Therefore, analytical modelling is necessary to understand the nature of the topology and interpret the results of either simulation or experiment. In addition to this, via analytical tools, design process such as choosing the arm inductance and submodule capacitance can be made easier. The parameters of the system considered in this work are presented in Table I.

\section{TABLE I. SYSTEM PARAMETERS FOR ELEVEN LEVEL MMI}

\begin{tabular}{|l|l|}
\hline Parameter & Value \\
\hline Grid Voltage, $\mathrm{v}_{\mathrm{g}}$ & $11 \mathrm{kV}$ \\
\hline Grid frequency, $\mathrm{f}$ & $50 \mathrm{~Hz}$ \\
\hline Filter inductance, $\mathrm{L}_{\mathrm{f}}$ & $8 \mathrm{mH}$ \\
\hline Filter Resistance, $\mathrm{R}_{\mathrm{f}}$ & $0.2 \Omega$ \\
\hline Switching frequency, fs & $5 \mathrm{kHz}$ \\
\hline Input DC voltage & $16 \mathrm{kV}$ \\
\hline SM capacitance & $1 \mu \mathrm{F}$ \\
\hline No. of SM per arm & 10 \\
\hline
\end{tabular}

Assumed that all submodule capacitors have the same voltage variations in time. If the capacitance of each submodule is $C_{S M}$, the capacitance of series connection of $\mathrm{N}$ submodules per arm, Carm, is expressed as

$c_{a r m}=\frac{C_{S M}}{N}$

The mathematical models of upper and lower arms are expressed in Eq. 2 and 3.

$\frac{V_{d x}}{2}-V_{L}=L_{a r m} \frac{d i_{L}}{d t}+R_{a r m} i_{L}-V_{T}$
$\frac{V_{d r}}{2}-V_{U}=L_{a r m} \frac{d i_{U}}{d t}+R_{a r m} i_{U}+V_{T}$

Here, $\mathrm{V}_{\mathrm{L}}$ and $\mathrm{V}_{\mathrm{U}}$ represent the upper and lower arm voltages, $R_{\text {arm }}$ and $L_{\text {arm }}$ is the arm resistance and arm inductor, $\mathrm{V}_{\mathrm{dc}}$ is the $\mathrm{DC}$ link voltage and $\mathrm{V}_{\mathrm{T}}$ is the terminal voltage. The output voltage is expressed as Equations (4) and (5) after 
rearranging the terms in Equations (2) and (3) which constitute the basis for control law in both output and circulating current.

$V_{\mathrm{T}}=\frac{\mathrm{V}_{\mathrm{U}}-\mathrm{V}_{\mathrm{L}}}{2}-\frac{\mathrm{R}_{\mathrm{arm}}}{2} \mathrm{i}_{0}-\frac{\mathrm{L}_{\mathrm{arm}}}{2} \frac{\mathrm{di}_{\mathrm{i}}}{\mathrm{dt}}$

$V_{d e}-\left(V_{U}+V_{L}\right)=2 L_{\text {arm }} \frac{d i_{\text {cr }}}{d t}+2 R_{\text {arm }} i_{c e}$

Where $i_{c c}$ is the circulating current. From Eq. (5), the circulating current depends only on the dc link voltage and the sum of arm voltages. The number of sub modules $(\mathrm{N})$ in each arm is computed using Eq.

(6)

$N \geq \frac{V_{d i c}}{V_{S M}}$

Submodule capacitor has considerable ripple voltage, which cannot be totally eliminated but its magnitude can be reduce by choosing appropriate submodule capacitance. Approximately $10 \%$ of ripple voltage in submodule capacitor is suitably considered. The stored energy $\left(E_{c}\right)$ of all submodule capacitor of a system is given in equation (7).

$E_{C}=\frac{a C v_{\text {II }}^{2}}{N}$

Arm inductor is connected in series with the submodule as shown in Fig.2, by this way it acts as a filter to the output current and also limits the circulation current. In [11] the submodule capacitance and arm inductance whose multiplication depends on submodule per arm $\mathrm{N}$ and operating frequency $\omega$, while satisfying the condition given in Eq.(8).

$L_{a r m} C_{S M}>\frac{5 N}{48 \omega^{2}}$

\section{A. PHASE DISPOSITION PWM TECHNIQUE}

Due to complexity in implementation of Selective Harmonic Elimination PWM and Space Vector PWM, Sinusoidal PWM technique is preferred. For higher number of voltage level and high power application multi-level carrier based modulation control strategy is used. The multilevel inverter of $\mathrm{n}$ levels would use $\mathrm{n}-1$ carriers. This approach works excellently when the carrier frequency is much higher than the modulation frequency.The most common carrier based PWMs are the Phase Disposition (PD).Fig.4 show the reference and carrier wave for eleven level MMI. The principle used in PD-PWM technique:

- In the PD PWM method, n-1 identical triangle carrier waves are placed one upon the other and compared to the modulation signal.
- All carrier signals have same frequency and amplitude.

- N-1 carrier signals are used which are vertically shifted to each other.

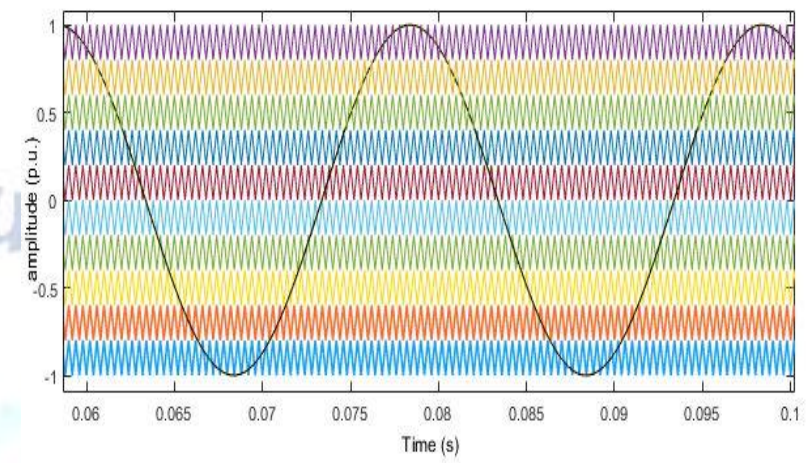

Fig.4: Reference and carrier signals for PD-PWM technique

Whenever the magnitude of the reference wave is greater than a carrier wave, positive going switching pulse is obtained. As the reference wave falls below each carrier the corresponding levels in the inverter output gets reduced.

\section{B. UTILIZATION FACTOR}

To quantify the effective use of available dc sources in a full cycle of the output voltage of the MLI, a performance indicator known as Utilization factor (UF) of input dc sources. Consider " $N$ " is number of dc sources, " $n$ " is the number of phase voltage levels, and " $X j$ " is the number of dc sources connected in MMI,then to obtain the jth level in phase voltage, then the UF can be defined as

$\mathrm{UF}=$

Sum of no of woltage sources connected to MnI at each phase woltage level [Total no of phase woltage levels: Total number of sources:

$\mathrm{UF}_{\mathrm{MMI}}=(1+2+2+2+2+2+2+2+2+1) /(11 * 2)$

$\mathrm{UF}_{\mathrm{MMI}}=0.909$

The percentage increase in utilization of dc sources in the MMI with respect to the RSC-SSPS [5] can be calculated as [(UF MMI - UF SSPS)/UF ssps] $\times 100$. Therefore, from the above mentioned calculations, it can be inferred the the utilization of dc source in MMI topology is increased by $15.53 \%$ when compared with RSC- SSPS MLI topology.

\section{V.CONVENTIONAL CLOSED-LOOP CONTROL STRATEGY FOR GRID-CONNECTED MMI}

When MMI connected to the grid as a front end converter, grid current is usually controlled in order to control the injected current in acceptable 
limit and also free from harmonics. In order to overcome the limitation of the PI in dealing with sinusoidal reference and harmonic disturbances, PI control is implemented in a synchronous $d-q$ rotating reference frame with grid frequency. In this control strategy, the DC link voltage is compared with set voltage and the reference current is derived according to error voltage. The three phase actual current is converted into $\mathrm{d}-\mathrm{q}$ component ofi $\mathrm{i}_{\mathrm{d}}$ and $\mathrm{i}_{\mathrm{q}}$.

Phase Locked Loop (PLL) tracks the frequency and phase of the input sinusoidal signal by using an internal frequency oscillator. The control system adjusts the internal oscillator frequency to keep the phase difference to Zero. The reference current $\left(i_{d}^{*}\right.$ and $\left.i_{q}^{*}\right)$ for the system is found using the equation (10)

$\left[\begin{array}{l}\mathbf{i}_{\mathrm{d}}{ }^{*} \\ \mathbf{i}_{\mathrm{q}}{ }^{*}\end{array}\right]=\frac{1}{\mathbf{v}_{\mathrm{gd}}^{2}+\mathrm{V}_{\mathrm{gq}}^{2}}\left[\begin{array}{cc}\mathbf{v}_{\mathrm{gd}} & -\mathbf{v}_{\mathrm{gq}} \\ \mathbf{v g q}_{\mathrm{gq}} & \mathbf{v}_{\mathrm{gd}}\end{array}\right]\left[\begin{array}{l}\mathbf{P}^{*} \\ \mathbf{Q}^{*}\end{array}\right]$

Here $\mathrm{P}^{*}$ and $\mathrm{Q}^{*}$ are the reference real and reactive powers. $V_{\mathrm{gd}}$ and $\mathrm{V}_{\mathrm{gq}}$ are the grid voltage in terms of d-q components. Reference current is compared with actual current and error is regulated through PI controllers to generate the modulation index.In order to obtain a good dynamic response and improve grid disturbance rejection, a grid voltage feed-forward can also use.

\section{VI.SIMULATION RESULTS}

This section discusses about simulation approach for grid connected MMI. The MMI based grid-connected system with PI controller is developed using MATLAB/Simulink environment. The MMI synthesizes 11 levels in its open-circuit output phase voltage, as depicted in Fig. 5, by using PD-PWM technique and its corresponding harmonic spectrum is shown in Fig. 6, which shows that the THD in voltage is $9.81 \%$. Table II shows the comparison of harmonic spectrum and utilization factor for MMI and SSPS. In this work, the Utilization factor for 11-level MMI is found to be increased to $15.53 \%$ when compared to SSPS.
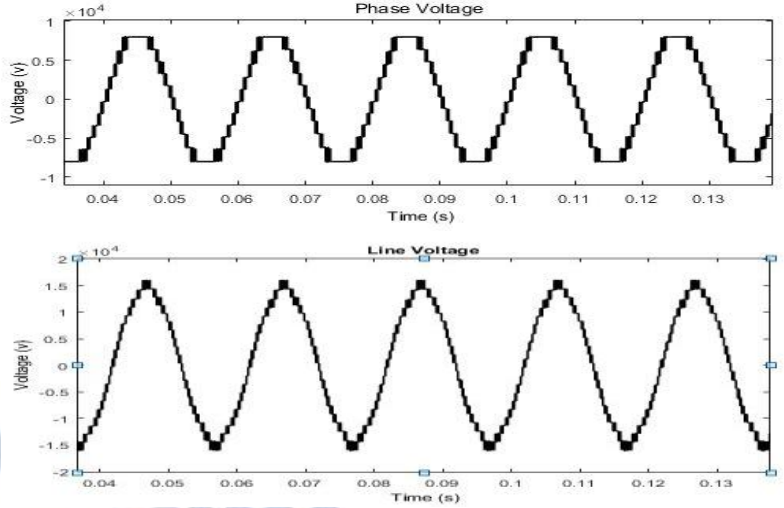

Fig.5: Line voltage and Phase Voltage for 11-level MMI

This specific merit of 11-level MMI is found to be advantageous for various grid - connected applications. Though MMI has high number of switches compared to SSPS, MMI has better Utilization factor and reduced harmonics.PI controller are used to regulate the current with respect to the reference real power as shown in Fig. 7 .

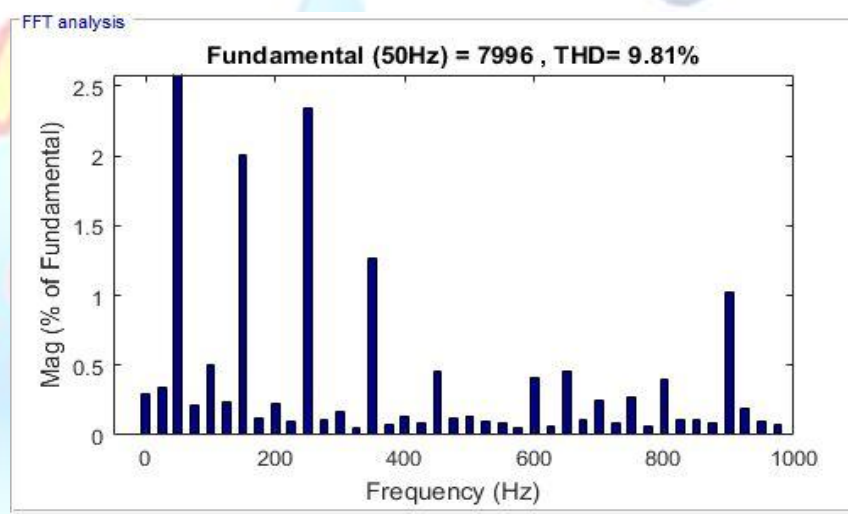

Fig.6: Harmonic Spectrum of Phase voltage for 11-level MMI

TABLEII.COMPARISON OF MMI WITH SSPS

\begin{tabular}{|l|l|l|l|}
\hline $\begin{array}{l}\text { Type of } \\
\text { Inverter }\end{array}$ & $\begin{array}{l}\text { Utilization } \\
\text { Factor }\end{array}$ & $\begin{array}{l}\text { \% increase in } \\
\text { Utilization } \\
\text { Factor }\end{array}$ & $\begin{array}{l}\text { Voltage } \\
\text { THD } \\
\text { (\%) }\end{array}$ \\
\hline $\left.\begin{array}{l}\text { Reduced } \\
\text { Switch } \\
\text { Count-Series/ } \\
\begin{array}{l}\text { Parallel } \\
\text { Switching } \\
\text { (RSCSSPS) of } \\
\text { Sources MLI } \\
\text { [4] }\end{array}\end{array}\right)$ & -7878 & 11.93 \\
\hline $\begin{array}{l}\text { 11-level } \\
\text { Modular } \\
\text { Multilevel } \\
\text { Inverter }\end{array}$ & 0.909 & 15.53 & \\
\hline
\end{tabular}




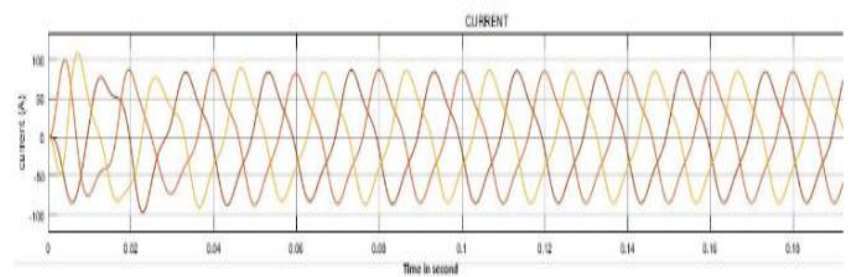

Fig.7: Current waveform for grid connected MMI

The optimal values of $\mathrm{Kp}$ and $\mathrm{Ki}$ are obtained as 100 and 200.Suppose the load connected to grid suddenly dropped from $12 \mathrm{~kW}$ to $4 \mathrm{~kW}$. The grid current can be controlled with respect to the reference power at the time of $0.15 \mathrm{~s}$ is shown in Fig .8. It can be observed that the PI controller experiences some overshoots/undershoot in power delivery and take less time to reach steady state.

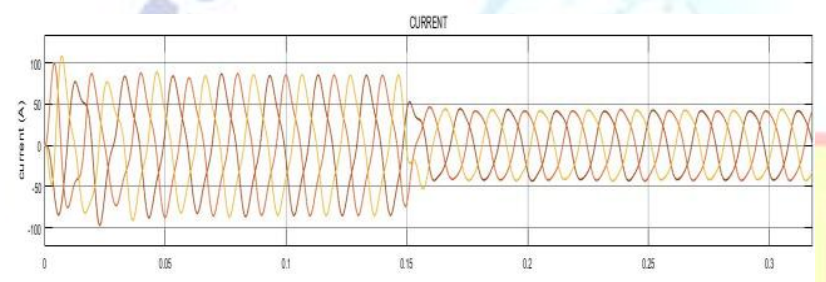

Fig. 8: Grid current change according to the real power

\section{CONCLUSION}

In this work, three phase $11 \mathrm{kV}$ grid connected Modular Multilevel Inverter with Phase Disposition Pulse width modulation technique was simulated in MATLAB and the performance was analyzed. The current control scheme with PI based $d-q$ reference frame controller was developed that balances the grid currents under varying load conditions. It is found that there is a significant reduction in THD when compared to RSC-SSPS topology. Further, MMI topology also utilizes the available dc source more effectively than its counterpart.

\section{REFERENCES}

[1] J.-S. Lai and F.Z. Peng, "Multilevel converters a new breed of power converters," Industry Applications Conference, Thirtieth IAS Annual Meeting, IAS '95., IEEE , Vol. 3, pp. 2348-2356,1995.

[2] J. Rodríguez., J.-S. Lai and F. Z. Peng, "Multilevel inverters: A survey of topologies, controls, and applications," IEEE Transactions on Industrial Electronics, Vol. 49, No. 4, August 2002.

[3] Y. Hinago and H. Koizumi, "A switched-capacitor inverter using series/parallel conversion with inductive load," IEEE Trans. Ind. Electron., vol. 59, no. 2, pp. 878-886, Feb. 2012
[4] Y. Hinago and H. Koizumi, "A single-phase multilevel inverter using switched series / parallel dc voltage sources," IEEE Trans. Ind. Electron., vol. 57, no. 8, pp. 2643-2650, Aug. 2010.

[5] G.Eshwar Gowd, P.C. Sekhar ," Real Time validation of a sliding mode controller for closed loop operation of Reduced Switch Count Multilevel Inverters," IEEE Systems Journal , vol. 13, no. 1, pp. 1042-1051, March 2019.

[6] A.Lesnicar, R.Marquardt, “ An Innivative modular multilevel converter topology suitable for a wide power range," Proceedings of the Power Tech Conference, Italy,23-26 June,2003.

[7] S.Rohner, S. Bernet, M, Hiller, R. Sommer,"Modulation, losses and semiconductor requirements of modular multilevel converters,"IEEETrans.Ind.Electron,vol.57, pp.2633-2642,2010

[8] L. Malesani, P. Tenti, " A novel hysteresis control method for current - controlled colatge-source PWM inverters with constantmodulation frequency," IEEE Trans. Ind.Appl, vol. 26, no.1, pp. 88-92, 1990.

[9] L. Malesani, P. Mattavelli, S. Buso," Robust dead-beat current control for PWM rectifiers and active filters," IEEE Trans. Ind.Appl, vol.35, no.3, pp. 613-620, 1999.

[10] M. Chinchilla, S. Arnalte, J.C. Burgos, J.L. Rodriguez, “ Power limits of grid connected modern wind energy systems," Renewable Energy, vol.31, no.9, pp. 1455-1470, 2005.

[11] Q. Tu, Z. Hu, H. Huang, "Parameter design principle of the arm inductor in modular multilevel inverter based HVDC," Power System Technology (POWERCON), International Conference on, pp.1-6, Oct. 2010.

[12] B. Gültekin and M. Ermiş, "Cascaded multilevel converter-based transmission STATCOM: System design methodology and development of a $12 \mathrm{kV} \pm 12$ MVAr power stage," Power Electronics, IEEE Transactions on, vol.28, no.11, pp.4930-4950, Nov. 2013. 